\title{
Doenças Respirrattóriơs
}

\section{Ambientais e Ocurpacionais}

\section{Apresentação}

Ao consultarmos a literatura médica específica, podemos avaliar a dimensão do tema "Doenças Respiratórias Ambientais e Ocupacionais - DRA0". No ano 2000, a American Thoracic Society (ATS) promoveu um encontro de especialistas para avaliar a interação do pulmão com o meio ambiente. 0 objetivo foi o de aprofundar a discussão desse problema de saúde pública, mais do que atual, priorizando abordagens que englobam desde os estudos de base populacional até as complexas interações celulares e moleculares decorrentes dos agentes encontrados no meio ambiente em geral. Foi destacado que o ar inalado, mesmo em condições de relativa pureza, contém um grande número de partículas das mais diversas origens, tais como poléns, proteínas animais e vegetais, poeiras inorgânicas, substâncias produzidas pela queima de combustíveis fósseis e de biomassa, erupções vulcânicas e pela degradação natural ocasionada pelas intempéries.

As doenças relacionadas com o trabalho, as assim chamadas "doenças profissionais", constituem um problema de difícil equacionamento, mesmo nos países desenvolvidos. Em 1995, estimativas americanas demonstravam um número de 125.000 a 350.000 casos novos de doenças ocupacionais por ano, cerca de 5,3 milhões de trabalhadores acometidos e um custo de U\$ 60 bilhões anuais relativos às despesas médicas e administrativas decorrentes desses agravos à saúde. As mais prevalentes são as doenças osteomusculares, respiratórias, dermatoses, perdas auditivas induzidas pelo ruído e intoxicações por produtos químicos.

As exposições ambiental e ocupacional aos agentes dispersos no ar que respiramos, os assim chamados aerodispersóides ou bioaerossóis, constituem-se, em nossos dias de extrema poluição atmosférica, desafiante problema de saúde pública. Embora reconhecidas ao longo dos séculos, e com substancial conhecimento adquirido em relação aos agentes responsáveis e medidas para a prevenção e o controle dessas exposições, ainda persistem ceifando vidas. Considerase que de $15 \%$ a $20 \%$ das doenças das vias aéreas e intersticiais podem ser atribuídas às exposições ocupacionais, segundo dados da ATS. Em 2000, nos EUA, foi estimado um custo de US\$ 140 bilhões relacionados com as doenças respiratórias de origem ocupacional, envolvendo, também, as despesas médicas e administrativas pertinentes.

Entre nós, os dados disponíveis são inconsistentes e imprecisos. Carecemos de uma base de dados de vigilância epidemiológica, a subnotificação ainda é predominante e, mesmo os profissionais da área da saúde afeitos a esse tema, na sua grande maioria ainda ignoram ou subestimam a etiologia ambiental ou ocupacional dessas doenças. Tal situação contribui para a precariedade do diagnóstico, e conseqüentemente para o deficiente sistema de coleta de dados, fundamental para a definição de políticas públicas de saúde. Por oportuno, indagamos: quantas vezes nós, os pneumologistas, perguntamos sobre a ocupação do nosso paciente, tentando estabelecer uma relação de nexo causal entre o seu trabalho, ao longo da sua vida, e a eventual hipótese diagnóstica? 


\section{Doenças Respirreattóriơas}

\section{Annbiemtais e Ocurpacionais}

Outras indagações são pertinentes: qual o número de trabalhadores expostos ao risco inalatório, a que agentes, em que nível de exposição, quantos adoeceram ou morreram exclusivamente devido a essas exposições (morbimortalidade), e quais os custos econômico e social decorrentes desses agravos? Seguramente as respostas serão inconsistentes, imprecisas ou até mesmo inexistentes.

Agradecemos a colaboração das sociedades afeitas ao assunto e aos colegas que participam da elaboração dos respectivos capítulos deste Suplemento. A sua elaboração visa a aprimorar o conhecimento sobre esse enfoque temático, proporcionando aos colegas uma leitura dirigida que os possa alentar para enfrentar a magnitude desse problema em nosso país e, quem sabe, despertar desafios institucionais ou pessoais mais do que necessários e urgentes.

0 presente suplemento procurará, portanto, trazer subsídios para a resolução destas pertinentes questões.

ERICSON BAGATIN, JOSÉ ALBERTO NEDER 